\title{
Online System Conciliation to Improve Knowledge and Perception of COVID-19 in the Local Community at Permata Bunda Hospital
}

\author{
Gontar Almansyah Siregar ${ }^{1}$, M. Fidel Ganis Siregar ${ }^{2}$, Zaimah Z Talah \\ ${ }^{1}$ Division of Gastroenterology, Department of Internal Medicine, Faculty of Medicine, University of Sumatera \\ Utara, Medan 20155, Indonesia \\ ${ }^{2}$ Department of Obstetrics and Gynecology, Faculty of Medicine, University of Sumatera Utara, Medan 20155, \\ Indonesia \\ ${ }^{3}$ Department of Nutrition, Faculty of Medicine, University of Sumatera Utara, Medan 20155, Indonesia
}

Corresponding Author: Gontar Almansyah Siregar

\begin{abstract}
COVID-19 is a world health problem with the first cases found in Wuhan, China. This case progressed until there were reports of deaths and there was a spread outside China, including Indonesia. The Government of the Republic of Indonesia responded to this as an emergency response by establishing a task force to accelerate the handling of corona which functions to prevent, detect and respond to Covid -19. One form of prevention of transmission is to increase knowledge by conducting counseling.
\end{abstract}

Method: Cross sectional study with 165 participants. This study uses a questionnaire measuring tool that is accessed online and analyzed into univariate and bivariate

Result: There was a significant difference in people's knowledge before and after counseling with a value of $p=0.000$. This is indicated by an increase in the post-test scores of participants who also experienced an increase after counseling with a mean post-test score of 74.2 compared to the pre-test score of 40.4.

Conclusion: General Public knowledge and understanding of Covid-19 is still quite low so that counseling through the online system has succeeded in increasing public knowledge which can be seen from the post-test scores that have increased

Keywords: COVID-19, online, perception, knowledge

\section{INTRODUCTION}

COVID-19 has become a world health problem. This case began with information from the World Health Organization (WHO) on December 31, 2019, which stated that there were cluster cases of pneumonia with unclear etiology in Wuhan City, Hubei Province, China. This case continues to grow until there are reports of deaths and there is a spread out of China, including to Indonesia. The total number of confirmed cases in Indonesia as of March 25, 2020 is 790 confirmed cases of COVID-19 from 24 provinces. North Sumatra, the number of confirmed cases of COVID-19 is 20 people. ${ }^{1,2}$

In response to the increase in cases, the President of the Republic of Indonesia raised the status of this disease to the Emergency Response stage on March 17, 2020. The President issued Presidential Decree No.7 of 2020 concerning the Task Force for the Acceleration of Corona Management, chaired by the Head of the National Disaster Management Agency (BNPB)). This cluster aims to increase national resilience in the health sector; accelerating the handling of COVID-19 through synergy between ministries / agencies and local governments; improve synergy in operational policy making; and 
increase readiness and capacity to prevent, detect and respond to COVID-19. ${ }^{1,2,3}$

Knowledge is the participant's understanding of a given topic. Knowledge is the ability to receive, retain, and use information, which is influenced by experience and skills. Most of the knowledge that a person has comes from both formal and informal education, personal and other experiences, the environment, and the mass media. ${ }^{4}$

To prevent transmission, it is necessary to increase public knowledge, one of which is through counseling about COVID-19, so we choose this community service activity in the form of online system education to increase knowledge and perceptions about COVID-19 in the general public.

\section{METHODS}

This research is a descriptive analytic study with a cross sectional design. The participants of this study were 165 ordinary people in the neighborhood around Permata Bunda Hospital in Medan. The inclusion criteria in this study were ordinary people who were in Permata Bunda Hospital and who could read and access the online questionnaire.

The gathering of participants in this study was to distribute flyers contains information regarding the time and place for the implementation of activities and then data collection of participants who will take part in extension activities through the online system regarding the COVID-19 disease. This research took place from May - November 2020. The measuring instrument in this study used a questionnaire given online. Counseling will be provided after participants fill out the online pretest questionnaire. Counseling in the form of interactive videos containing knowledge about COVID-19. After counseling, participants will take a post test to assess whether there has been a change in knowledge of the general public regarding COVID-19.

Data analysis was carried out by univariate and bivariate (Wilcoxon test) using SPSS edition 21st (SPSS Inc .. Chicago). A $\mathrm{P}$ value $<0.05$ with a $95 \%$ confidence interval was considered statistically significant.

\section{RESULT}

Table 1. Value of knowledge before and after counseling

\begin{tabular}{|l|l|r|r|}
\hline \multicolumn{2}{|c|}{ Table 1. Value of knowledge before and after counseling } \\
\hline \multirow{2}{*}{$\mathrm{N}$} & Valid & \multicolumn{1}{|c|}{ pretest } & \multicolumn{1}{c|}{ posttest } \\
\cline { 2 - 4 } & Missing & 165 & 165 \\
\hline Mean & 0 & 0 \\
\hline Mode & 40,4303 & 74,2000 \\
\hline Minimum & 21.00 & $71.00 \mathrm{a}$ \\
\hline Maximum & 7.00 & 29.00 \\
\hline
\end{tabular}

Table 2. Value of the Pretest

\begin{tabular}{|r|r|r|r|r|r|}
\hline \multicolumn{7}{|c|}{ Table 2. Value of the Pretest } \\
\hline \multirow{3}{*}{ Valid } & Frequency & Percent & Valid Percent & Cumulative Percent \\
\cline { 2 - 6 } & 7.00 & 12 & 7.3 & 7.3 & 7.3 \\
\cline { 2 - 6 } & 14.00 & 19 & 11.5 & 11.5 & 18.8 \\
\cline { 2 - 6 } & 21.00 & 30 & 18.2 & 18.2 & 37.0 \\
\cline { 2 - 6 } & 29.00 & 23 & 13.9 & 13.9 & 50.9 \\
\cline { 2 - 6 } & 36.00 & 15 & 9.1 & 9.1 & 60.0 \\
\cline { 2 - 6 } & 43.00 & 16 & 9.7 & 9.7 & 69.7 \\
\cline { 2 - 6 } & 50.00 & 6 & 3.6 & 3.6 & 73.3 \\
\cline { 2 - 6 } & 57.00 & 4 & 2.4 & 2.4 & 75.8 \\
\cline { 2 - 6 } & 64.00 & 4 & 2.4 & 2.4 & 87.2 \\
\cline { 2 - 6 } & 71.00 & 7 & 4.2 & 4.2 & 87.9 \\
\cline { 2 - 6 } & 79.00 & 9 & 5.5 & 5.5 & 95.2 \\
\cline { 2 - 6 } & 86.00 & 12 & 7.3 & 7.3 & 100.0 \\
\cline { 2 - 6 } & 93.00 & 4 & 2.4 & 2.4 & 2.4 \\
\cline { 2 - 6 } & 100.00 & 4 & 2.4 & 100.0 & \\
\cline { 2 - 6 } & Total & 165 & 100.0 & & \\
\hline
\end{tabular}

The results of this study indicate that the knowledge of the general public at Permata Benda Hospital is still quite low. This is evident from mean score of the pre test is 40.4 with the lowest score of 7 and the highest of 100 . However, general public knowledge about COVID-19 after an online system of education through video has 
increased. Increased knowledge of thegeneral public at Permata Bunda Hospital is assessed from the post test score which has increased mean score around 74.2 with the lowest score of 29 and the highest score of 93.

From the results of the pretest values that can be seen in table 2, there are around 12 people $(7.3 \%)$ who have the lowest pretest value and about 4 people $(2.4 \%)$ who have the highest pretest value. Most of the
21 pretest scores were owned by participants, around 30 people (18.2\%). However, after counseling was carried out, the post test scores listed in table 3 of the participants experienced an increase with the lowest score of around 29 found in 1 person $(0.6 \%)$ and the highest score of 93 found in 15 people $(9.1 \%)$. The post test scores of 71 and 79 were mostly owned by participants, around 41 people $(24.3 \%)$.

Table 3. Post Test Values

\begin{tabular}{|c|c|c|c|c|c|}
\hline \multicolumn{6}{|c|}{ posttest } \\
\hline & & Frequency & Percent & Valid Percent & Cumulative Percent \\
\hline \multirow[t]{10}{*}{ Valid } & 29.00 & 1 & .6 & .6 & .6 \\
\hline & 43.00 & 1 & .6 & .6 & 1.2 \\
\hline & 50.00 & 2 & 1.2 & 1.2 & 2.4 \\
\hline & 57.00 & 14 & 8.5 & 8.5 & 10.9 \\
\hline & 64.00 & 26 & 15.8 & 15.8 & 26.7 \\
\hline & 71.00 & 41 & 24.8 & 24.8 & 51.5 \\
\hline & 79.00 & 41 & 24.8 & 24.8 & 76.4 \\
\hline & 86.00 & 24 & 14.5 & 14.5 & 90.9 \\
\hline & 93.00 & 15 & 9.1 & 9.1 & 100.0 \\
\hline & Total & 165 & 100.0 & 100.0 & \\
\hline
\end{tabular}

\section{Comparison of the level of knowledge before and after counseling}

Based on Wilcoxon analysis, there is a significant relationship between the knowledge before and after counseling $(\mathrm{p}=$ 0.00 ) with a lower $\mathrm{P}$ value $<0.05$, it is concluded that $\mathrm{Ha}$ is acceptable.

Table 4. Wilcoxon analysis

\begin{tabular}{|l|r|}
\hline & \multicolumn{2}{|c|}{ posttest - pretest } \\
\hline $\mathrm{Z}$ & $-10.803 \mathrm{~b}$ \\
\hline Asymp. Sig. (2-tailed) & .000 \\
\hline
\end{tabular}

Based on table 5 the comparison of the level of knowledge before and after counseling. From the table, it is found that 4 respondents with pre-test scores are higher than the post-test scores. A total of 152 respondents with posttest scores higher than pretest scores, and 9 respondents with posttest scores equal to pretest scores.

Table 5. Comparison of the level of knowledge before and after counseling

\begin{tabular}{|c|c|c|c|c|}
\hline \multicolumn{5}{|c|}{ Ranks } \\
\hline \multirow{3}{*}{ posttest - pretest } & N & Mean Rank & Sum of Ranks \\
\cline { 2 - 5 } & Negative Ranks & $4 \mathrm{a}$ & 10.50 & 42.00 \\
\cline { 2 - 5 } & Positive Ranks & $152 \mathrm{~b}$ & 80.29 & 12204.00 \\
\cline { 2 - 5 } & Ties & $9 \mathrm{c}$ & & \\
\cline { 2 - 5 } & Total & 165 & & \\
\hline a. posttest $<$ pretest & & & \\
\hline b. posttest $>$ pretest \\
\hline c. posttest $=$ pretest
\end{tabular}

\section{DISCUSSION}

In this study, it was seen that the participants' level of knowledge about Covid-19 was low. Knowledge was assessed with mean pretest score of 40.4. Most of the research subjects had better knowledge after Covid-19 counseling. However, the results in this study were different from other studies which reported $76.9 \%$ respondents have good knowledge. 5 In another study, in Malaysia, the level of knowledge of the community was also about $80.5 \%$.6 However, differences in the results of this study could be influenced by various factors such as age and educational background. 


\section{CONCLUSION}

The public's knowledge and understanding of Covid-19 is still quite low so that counseling through the online system has succeeded in increasing public knowledge which can be seen from the posttest scores that have increased. The difference in public knowledge before and after the extension was carried out also had a significant difference with a value of $\mathrm{p}=$ 0.000

\section{Acknowledgement: None}

\section{Conflict of Interest: None}

\section{Source of Funding: None}

\section{Ethical Approval: Approved}

\section{REFERENCES}

1. Yurianto A. Guidelines for the prevention and control of coronavirus disease (COVID19). Ministry of Health of the Republic of Indonesia. 2020

2. Susilo A, et al. Coronavirus Disease 2019: A Review of Recent Literature. Indonesian Journal of Internal Medicine. 2020
3. Adisasmito W, et al. Guidelines for Rapid Medical and Public Health Management of COVID 19 in Indonesia. Ministry of Health of the Republic of Indonesia. 2020

4. Siltrakool, B. 2017. Assessment of Community Pharmacists' Knowledge, Attitude and Practice Regarding NonPrescription Antimicrobial Use and Resistance in Thailand. $\mathrm{PhD}$ Thesis. University of Hertfordshire

5. Jesica \& Rizma. Knowledge related to Coronavirus disease (Covid - 19) Prevention Efforts in Indonesia. Higeah Journal of Public Health Research \& Developement 2020.

6. Arina et al. Public Knowledge, attitudes and practices towards Covid - 19: A Cross sectional study in Malaysia. Universiti Kebangsaan Malaysia. 2020

How to cite this article: Siregar GA, M. Fidel Ganis Siregar, Talah ZZ. Online system conciliation to improve knowledge and perception of COVID-19 in the local community at Permata Bunda Hospital. International Journal of Research and Review. 2021; 8(8): 203-206. DOI: https://doi.org/10. 52403/ijrr.20210828 